\title{
SERAPILHEIRA E TEORES DE NUTRIENTES EM ARGISSOLO SOB DIFERENTES MANEJOS NO NORTE DO PIAUÍ1
}

\author{
Sandra Santana de Lima², Luiz Fernando Carvalho Leite ${ }^{3}$, Adriana Maria de Aquino ${ }^{4}$, Francisco das \\ Chagas Oliveira ${ }^{5}$ e Antonio Alberto Jorge Farias Castro ${ }^{6}$
}

\begin{abstract}
RESUMO - Este trabalho teve como objetivos avaliar o estoque de serapilheira acumulada e quantificar os teores de N, P, K, Ca e Mg em sistemas agroflorestais com seis (SAF6) e dez (SAF10) anos de adoção, sistema com base ecológica de três anos (SE3), agricultura de corte e queima (ACQ) e floresta nativa (FN) no Município de Esperantina, norte do Piauí. As coletas foram realizadas nos períodos chuvoso e seco do ano 2007, sendo a serapilheira separada nas frações folhas e galhos para a estimativa dos estoques acumulados sobre o solo. Os maiores estoques da fração folhas foram observados na FN $\left(3,8 \mathrm{Mg}(\mathrm{t}) \mathrm{ha}^{-1}\right)$, período seco; e da fração galhos no SAF10 (2,2 Mg(t) ha $\left.{ }^{-1}\right)$, no período chuvoso. Os SAFs apresentaram os maiores teores de nutrientes nas frações da serapilheira e entre os nutrientes, e a concentração de $\mathrm{N}$ foi superior à dos demais nutrientes, em ambos os períodos. A estimativa de transferência dos nutrientes pela serapilheira obedeceu à sequência $\mathrm{N}>\mathrm{Ca}>\mathrm{K}>\mathrm{P}>\mathrm{Mg}$. Os valores de estoques da serapilheira, teores e aportes de nutrientes nos SAFs evidenciam a contribuição do manejo agroflorestal para a qualidade do solo e a sustentabilidade econômica do sistema.
\end{abstract}

Palavras-chave: Biomassa, Macronutrientes e Sistemas agroflorestais.

\section{LITTER AND NUTRIENT CONTENTS IN ARGISOL UNDER DIFFERENT MANAGEMENTS IN NORTHERN PIAUÍ}

\begin{abstract}
This work aimed to evaluate litter deposition and quantify contents of N, $P, K, C a$ and $M g$ in agroforest systems six (AFS6) and ten (AFS10) years after implantation, in three-year old ecological based systems (ES3), slash-and-burn agriculture (SBA) and native forest (NF), all located in Esperantina, northern region of Piaui, Brazil. Collections were carried out in the wet and dry seasons of 2007. The litter was separated into leaves and branches and weighted to estimate the deposition on the soil. The highest leaf depositions were found in $\mathrm{NF}\left(3.8 \mathrm{Mg} \mathrm{ha}^{-1}\right)$, in the dry season, whereas for branches, in the AFS1O $\left(2.2 \mathrm{Mg} \mathrm{ha}^{-1}\right)$, in the wet season. AFS showed the highest nutrient contents in the litter fractions, and, among them the N concentration was higher than the others, in both seasons. The estimate transfer of nutrients by the litter followed the sequence $N>C a>K>P>M g$. The values for litter deposition and contents and input of nutrients in the AFS systems show the contribution of the agroforest management to soil quality and the economic sustainability of the system.
\end{abstract}

Keywords: Biomass, Macronutrients and Agroforest systems

\section{INTRODUÇÃO}

A serapilheira constitui-se na camada de restos vegetais e animais disposta na superfície do solo (BORÉM e RAMOS, 2002). Sua produção, seguida da decomposição, representa o principal meio de transferência de matéria orgânica e da maior parte dos macro e micronutrientes do solo, possibilitando a sua reabsorção pelos vegetais (KÖNIG et al., 2002; SANTANA, 2005; SCHUMACHER et al., 2004).

\footnotetext{
${ }^{1}$ Recebido em 14.02.2008 e aceito para publicação em 14.10.2009.

${ }^{2}$ Programa de Pós-Graduação em Agronomia - Ciência do Solo, na Universidade Federal Rural do Rio de Janeiro .E-mail: <sandra.biologa@hotmail.com>.

${ }^{3}$ Empresa Brasileira de Pesquisa Agropecuária, Centro de Pesquisa Agropecuária do Meio-Norte - Teresina, PI - Brasil. E-mail: <luizf@cpamn.embrapa.br>.

${ }^{4}$ Empresa Brasileira de Pesquisa Agropecuária, Centro Nacional de Pesquisa de Agrobiologia - Nova Friburgo, RJ - Brasil. E-mail: <adriana@cnpab.embrapa.br>.

${ }^{5}$ Analista da Embrapa Meio Norte. E-mail: <oliveira@cpamn.embrapa.br>.

${ }^{6}$ Universidade Federal do Piauí, Centro de Ciências da Natureza, (BIOTEN) - Teresina, PI-Brasil .E-mail: <aajfcastro@uol.com.br>.
} 
A quantidade de serapilheira e seu conteúdo de nutrientes aportados ao solo refletem na sua capacidade produtiva e no seu potencial de recuperação ambiental, tendo em vista as modificações que irão ocorrer nas características químicas do solo (SCHUMACHER et al., 2004). A qualidade de serapilheira influencia a abundância, composição e atividade dos microrganismos e fauna do solo, que participam da decomposição do material e determinam a taxa de decomposição e dinâmica de nutrientes (POLYAKOVA e BILLOR, 2007).

Por meio da decomposição de resíduos vegetais e animais que chegam ao solo, a serapilheira pode contribuir para o acúmulo de matéria orgânica nesse solo (ALVES et al., 2005) e completa o ciclo dos elementos nutricionais, tal fato possibilita que parte do carbono (C) incorporado à biomassa pela fotossíntese retorne à atmosfera como $\mathrm{CO}_{2}$ e ocorra o retorno ao solo de significativa quantidade de nutrientes absorvidos pelas plantas (HOBBELEN e VAN GESTEL, 2007; SCHUMACHER et al., 2003). No entanto, a concentração de nutrientes na serapilheira depende das características morfológicas e fisiológicas das espécies de plantas, da capacidade de translocação do nutriente antes da senescência, do tipo de solo e da proporção de folhas em relação aos demais componentes (VOHLAND e SCHROTH, 1999; KÖNIG et al., 2002).

Nos sistemas agroflorestais (SAFs), a biomassa da serapilheira é proveniente do manejo e do arranjo das plantas, sobretudo da poda direcionada das árvores e outras espécies, como arbustos (SILVEIRA et al., 2007). A camada de serapilheira tem papel fundamental na manutenção da sustentabilidade por disponibilizar gradualmente o retorno dos nutrientes para as plantas (POLYAKOVAe BILLOR, 2007). Além disso, pode indicar a capacidade produtiva da floresta ao relacionar os nutrientes disponíveis com as necessidades nutricionais de dada espécie arbórea (FIGUEIREDO FILHO et al., 2003).

Embora os SAFs favoreçam a formação da serapilheira e o aumento do aporte de nutrientes, muitos produtores ainda utilizam a agricultura com base no corte e queima. Quando ocorre a queima da vegetação, a combustão do material provoca a liberação dos elementos químicos como $\mathrm{P}, \mathrm{Ca}, \mathrm{Mg}$ e do C, porém dificulta ou impede o processo de reciclagem (LOUZADA et al., 2003). A queima dos resíduos vegetais eleva os teores das bases trocáveis, e poderá, no longo prazo, diminuir a fertilidade do solo, uma vez que as cinzas são facilmente carreadas por lixiviação e, ou, erosão (MENDONZA et al., 2000). Apesar da degradação ocasionada por esse tipo de manejo, grande parte dos agricultores na região Norte do Piauí a utilizam, aproveitando a disponibilidade temporária de nutrientes.

A serapilheira produzida nos sistemas tem sido reconhecida como um dos agentes promotores da recuperação de áreas degradadas, por meio dos processos de decomposição e ciclagem de nutrientes (COSTA et al., 2004). Apesar disso, são inexistentes estudos sobre a ciclagem de nutrientes nesses sistemas no Estado do Piauí. Nesse sentido, este trabalho objetivou avaliar o estoque de serapilheira acumulada e seus teores de nutrientes em sistemas agroflorestais com diferentes idades de adoção, sistema com base ecológica, agricultura de corte e queima e floresta nativa de Cerrado.

\section{MATERIAL E MÉTODOS}

\section{1. Localização e Descrição da Área de Estudo}

O estudo foi realizado no Município de Esperantina (03 54' 07' 'S e 42 14 ' 02"' W, altitude 59 m), região Norte do Estado do Piauí, cujo clima se enquadra no tipo tropical subúmido, com duas estações bem definidas, uma chuvosa e outra seca, e temperaturas anuais médias de $26{ }^{\circ} \mathrm{C}$ para mínima e de $34{ }^{\circ} \mathrm{C}$ para máxima. A precipitação média anual é de $1.400 \mathrm{~mm}$ e os maiores índices pluviométricos são concentrados entre os meses de janeiro e maio. A região é caracterizada por apresentar formação vegetal predominante de transição entre Cerrado e floresta secundária mista, possuindo extensas áreas com babaçuais. O solo é classificado como Argissolo Vermelho-Amarelo distrófico, textura franco-arenosa (SANTOS et al., 2006). Os resultados das análises de solo são apresentados na Tabela 1 .

Foram estudados cinco sistemas: sistema com base ecológica com três anos de adoção (SE3), sistemas agroflorestais com seis (SAF6) e dez (SAF10) anos de adoção; uma área manejada com agricultura de corte e queima (ACQ) e uma floresta nativa (FN). O tamanho de cada área estudada compreende 1 ha. No SE3, a prática do corte e queima da vegetação foi utilizada até o ano de 2003. A partir de 2004, após a regeneração natural da vegetação, foi realizado um roço no período seco e outro no período chuvoso, para garantir o crescimento das espécies agrícolas cultivadas no local. De acordo com o proprietário, foram aplicadas $10 \mathrm{t}$ de esterco de caprinos em pequena quantidade (menos 
Tabela 1 - Características químicas de um Argissolo Vermelho-Amarelo distrófico, na camada de 0-10 cm, sob sistema com base ecológica com três anos de adoção (SE3), sistemas agroflorestais com seis (SAF6) e dez anos de adoção (SAF10), agricultura de corte e queima (ACQ) e floresta nativa (FN).

Table 1 - Chemical characteristics of a dystrophic Red-Yellow Argisol, 0-10 cm layer, under three-year old ecological system (ES3), agroforest systems with six (AFS6) and ten (AFS10) years old, slash-and-burn agriculture (SBA) and native forest $(N F)$.

\begin{tabular}{|c|c|c|c|c|c|c|c|}
\hline \multirow[t]{2}{*}{ Sistemas } & $\bar{C}$ & $\mathrm{~N}$ & \multirow{2}{*}{$\frac{\mathrm{P}}{\mathrm{mg} \mathrm{dm^{-3 }}}$} & $\mathrm{K}$ & $\mathrm{Ca}$ & $\mathrm{Mg}$ & $\mathrm{A} 1$ \\
\hline & & & & \multicolumn{4}{|c|}{$\mathrm{cmol}_{\mathrm{c}} \mathrm{dm}^{-3}$} \\
\hline SE 3 & 2,3 & 0,3 & 2,0 & 0,3 & 3,4 & 0,7 & $\overline{0,0}$ \\
\hline SAF6 & 3,8 & 0,3 & 5,8 & 0,5 & 3,1 & 2,2 & 0,1 \\
\hline SAF10 & 4,0 & 0,4 & 12,2 & 0,5 & 8,8 & 1,8 & 0,0 \\
\hline ACQ & 1,7 & 0,8 & 2,0 & 0,7 & 3,5 & 0,5 & 0,1 \\
\hline FN & 3,0 & 0,2 & 1,7 & 0,3 & 0,9 & 1,1 & 1,5 \\
\hline
\end{tabular}

Fonte: LIMA, 2008.

que $1 / 2$ por hectare). Nesse sistema foram consorciadas espécies como mamoeiro (Carica papaya L.), cajueiro (Anacardium occidentale L.), melancieira (Citrullus vulgaris Schrad.), maxixeiro (Cucumis anguria L.) e bananeira (Musa paradisiaca L.). As espécies frutíferas foram distribuídas de forma aleatória na área, sendo a maior proporção representada pelo cajueiro, com, cerca de dez plantas.

Com relação ao SAF6, até 2001 a área era mantida com agricultura de corte e queima. Em 2002, essa prática foi substituída pelo roço da vegetação secundária, excluindo-se algumas espécies arbóreas pelo seu potencial madeireiro e valor cultural, sendo o material vegetal proveniente do manejo utilizado como cobertura do solo. O segundo roço foi efetuado no período chuvoso, para permitir o crescimento das espécies agrícolas. Além disso, foi adicionada ao solo palha de carnaúba como cobertura. No sistema SAF6, foram cultivados, nesse sistema: milho (Zea mays L.) e algodão (Grossypium herbaceum L.) consorciados com caju (Anacardium occidentale L.), banana (Musa paradisiaca L.), amendoim (Arachis sylvestris (A.Chev.) A.Chev.), pinha (Annona squamosa L.) e mamona (Ricinus communis L.), além de espécies florestais como jatobá (Hymenaea sp.), jurubeba (Solanum sp.), pau-d' arco-amarelo (Tabebuia serratifolia), carnaúba (Copernicia prunifera Mill.) e mandacaru (Cereus jamacaru DC.). O arranjo espacial das espécies arbóreas nativas e frutíferas foi inteiramente aleatório. A espécie Anacardium occidentale L. (cajueiro) predominava sobre as frutíferas, com cerca de 30 plantas.

Na área com SAF10, em 1997 o corte e a queima foram substituídos por um manejo sem queima ou incrementos químicos industrializados. O material vegetal decorrente do roço, antes queimado, passou a ser utilizado como cobertura do solo. A partir daí, ao longo do tempo foram introduzidas espécies frutíferas e paralelamente, permitiu-se a regeneração natural de plantas pioneiras, as quais sofreram podas periódicas. Além disso, foram adicionados ao solo esterco de caprinos e todos os resíduos orgânicos decorrentes do consumo da família. Nesse sistema foram cultivados milho (Zea mays L.), abóbora (Curcubita pepo L.), fava (Phaseolus lunatus L.), mandioca (Manihot esculeta Crantz.), batata-doce (Ipomoea batatas (L.) Lam.) e algodão (Grossypium herbaceum L.) consorciados com acerola (Malpighia glabra L.), mamão (Carica papaya L.), goiaba (Psidium guajava L.), banana (Musa paradisiaca L.), caju (Anacardium occidentale L.), manga (Mangifera indica L.), pinha (Annona squamosa L.), pitomba (Talisia esculenta Raldlk.), mamona (Ricinus communis L), urucum (Bixa orellana L.), gergelim (Sesamum indicum L.), paud'arco (Tabebuia sp.), babaçu (Attalea speciosa Mart. ex Spreng.), gonçalo-alves (Astromiun fraxinifolium Schott), tamboril (Enterolobium sp.), jatobá (Hymenaea sp.), aroeira (Myracrodruon urundeuva Allemao), mufumbo (Combretum sp.) e unha-de-gato (Mimosa sp.). Assim, a exemplo dos demais sistemas estudados, as espécies arbóreas e frutíferas foram distribuídas de forma aleatória com maior densidade do cajueiro, cerca de 40 plantas por hectare e em menor proporção, mamona, banana e manga.

Na área de ACQ ocorreram, após o período de pousio, em 2005, o manejo do corte e a queima da vegetação. Em 2006, a área foi mantida com monocultura de milho. A FN foi caracterizada por apresentar vegetação de floresta semidecídua preservada, onde foram observadas espécies de Cerrado e Caatinga.

R. Árvore, Viçosa-MG, v.34, n.1, p.75-84, 2010 


\section{2. Estimativa do estoque da serapilheira acumulada}

Em cada área foram realizadas coletas em duas épocas, no final dos períodos chuvoso e seco de 2007 , utilizando-se 15 amostras simples, para formar cinco amostras compostas de serapilheira acumulada em cada área. A coleta da serapilheira foi realizada com um quadrado vazado de madeira com 25 x $25 \mathrm{~cm}$ e uma faca para sua remoção e posterior acondicionamento em sacos de papel. Foram considerados como componentes da serapilheira folhas e galhos com diâmetro menor que $2 \mathrm{~cm}$, de acordo com Arato et al. (2003).

A separação das amostras nas frações folhas e galhos foi realizada no Laboratório de Bromatologia da Embrapa Meio Norte. Em seguida, o material foi seco em estufa a $65^{\circ} \mathrm{C}$ até atingir peso constante; após a secagem, foi pesado, determinando-se, assim, a biomassa das amostras, que foram extrapoladas para a estimativa de massa seca por hectare.

\subsection{Atributos químicos da serapilheira}

Para avaliação dos teores dos macronutrientes, a serapilheira foi triturada em moinho, acondicionada em sacos plásticos hermeticamente fechados e etiquetados para posterior análise. Na extração dos elementos químicos do material vegetal coletado foi utilizado o método da digestão úmida, recomendado pela Embrapa (1997).
Para determinar os teores de nitrogênio (N), utilizou-se a digestão sulfúrica pelo método de Kjeldhal (EMBRAPA, 1997). O fósforo (P) foi determinado por espectrofotometria com azul-de-molibidênio, o potássio $(\mathrm{K})$ por fotometria de chama e o cálcio ( $\mathrm{Ca}$ ) e magnésio $(\mathrm{Mg})$ por espectrofotometria de absorção atômica (EMBRAPA, 1997).

\section{4. Análises dos dados}

Foram realizadas Análises de Variância (ANOVA) e aplicado o teste de Tukey a 5\%, pelo programa SPSS, para verificar as diferenças entre as médias das análises químicas da serapilheira em cada área estudada.

\section{RESULTADOS}

No período chuvoso, o estoque da fração folhas foi maior no SAF10 (3,0 Mg), diferindo dos demais sistemas, enquanto o menor estoque foi observado no ACQ $\left(0,1 \mathrm{Mg} \mathrm{ha}^{-1}\right)$. No período seco, os maiores estoques $(\mathrm{p} \leq 0,05)$ da fração folhas foram verificados na FN (3,8 Mg(t) ha $\left.{ }^{-1}\right)$ e ACQ (3,6 Mg(t) ha-1), diferindo estatisticamente do SAF10, SAF6 e SE3 (Tabela 1). Os estoques de folhas obtidos no SAF10 (2,9 Mg(t) $\left.\mathrm{ha}^{-1}\right)$ e SAF6 (2,6 Mg(t) ha $\left.{ }^{-1}\right)$ foram semelhantes e diferiram do observado no SE3 (1,6 Mg(t) ha-1). Entre os períodos de coleta, os estoques da fração folhas nos sistemas SE3 e SAF10 não diferiram, no entanto os sistemas SAF6, ACQ e FN foram significativamente diferentes (Tabela 2).

Tabela 2 - Estoque das frações folha e galho da serapilheira acumulada nos períodos chuvoso e seco $\left(\mathrm{Mg} \mathrm{ha}^{-1}\right)$, sob sistema ecológico com três anos (SE3), sistemas agroflorestais com seis (SAF6) e 10 anos (SAF10), agricultura de corte e queima (ACQ) e floresta nativa (FN).

Table 2 - Leaf and branch fractions of litter accumulated during wet and dry seasons $\left(\mathrm{t} \mathrm{ha} \mathrm{H}^{-1}\right)$, under three-year old ecological system (ES3), agroforest systems with six (AFS6) and ten (AFS10) years old, slash-and-burn agriculture (SBA) and native forest $(N F)$.

\begin{tabular}{|c|c|c|c|c|c|}
\hline \multicolumn{6}{|c|}{ Folhas } \\
\hline & SE3 & SAF 6 & SAF10 & ACQ & FN \\
\hline & & & & & \\
\hline P.chuvoso & $1,2 \mathrm{bcA}$ & $1,4 \mathrm{bcB}$ & 3,0 aA & $0,1 \mathrm{cB}$ & $2,6 \mathrm{abB}$ \\
\hline P. seco & $1,6 \mathrm{bA}$ & $2,6 \mathrm{abA}$ & $2,9 \mathrm{abA}$ & $3,6 \mathrm{aA}$ & 3,8 aA \\
\hline \multicolumn{6}{|c|}{ Galhos } \\
\hline P.chuvoso & $1,2 \mathrm{bA}$ & $0,6 \mathrm{bcA}$ & $2,2 \mathrm{aA}$ & $0,3 \mathrm{cA}$ & $1,1 \mathrm{bA}$ \\
\hline P. seco & $0,6 \mathrm{bB}$ & $0,6 \mathrm{bA}$ & $1,1 \mathrm{aB}$ & $0,5 \mathrm{bA}$ & $0,9 \mathrm{abA}$ \\
\hline Total & $4,6 b$ & $5,2 \mathrm{~b}$ & $9,3 \mathrm{a}$ & $5,45 \mathrm{~b}$ & $8,41 \mathrm{a}$ \\
\hline
\end{tabular}

Médias seguidas de letras minúsculas diferentes na linha (entre sistemas) e letras maiúsculas diferentes na coluna (entre períodos) indicam diferenças significativas pelo teste de Tukey a $5 \%$ de probabilidade.

R. Árvore, Viçosa-MG, v.34, n.1, p.75-84, 2010 
Em relação à fração galhos, no período chuvoso observou-se no SAF10 (2,2 Mg(t) ha $\left.{ }^{-1}\right)$ estoque superior $(\mathrm{p} \leq 0,05)$ ao obtido pelos demais sistemas, enquanto o menor valor foi verificado no ACQ $\left(0,3 \mathrm{Mg}(\mathrm{t}) \mathrm{ha}^{-1}\right)$. Diferentemente do que se viu na fração folhas em relação aos períodos de coletas, os estoques de galhos apresentaram decréscimo do período chuvoso para o período seco, exceto em ACQ $\left(0,5 \mathrm{Mg}(\mathrm{t}) \mathrm{ha}^{-1}\right)$. Apenas os sistemas SE3 e SAF10 apresentaram diferenças significativas de estoque na fração galhos entre os períodos de coletas (Tabela 1 ). A estimativa anual de serapilheira no SAF10 (9,3 Mg(t) ha-1) e FN (8,4 $\left.\mathrm{Mg}(\mathrm{t}) \mathrm{ha}^{-1}\right)$ não diferiu entre si e foi superior aos obtidos nos demais sistemas, que foram estatisticamente iguais (Tabela 2).

Os SAFs e SE3 apresentaram as maiores concentrações de nutrientes no período chuvoso. Em ambos os períodos, os maiores teores de nitrogênio (N) na fração folhas foram observados no SAF10. No período seco, o maior teor de $\mathrm{N}(\mathrm{p} \leq 0,05)$ nas folhas foi visto no SAF10 superior aos demais sistemas e o menor, observado na FN. Entretanto, verificou-se decréscimo em relação ao período chuvoso, diferindo estatisticamente entre períodos de coleta em todos os sistemas. No período chuvoso, os teores de P na fração folhas foram os menores observados nos sistemas ACQ e FN, diferindo dos demais sistemas. Porém, no período seco os teores de $\mathrm{P}$ da fração folhas foram praticamente o dobro em todos os sistemas, comparativamente ao observado no período chuvoso (Tabela 3).

Quanto ao K no período chuvoso, os maiores teores foram observados no SE3 e SAF6. No período seco, o SE3 diferiu de todos os sistemas, e entre o SAF6 e SAF10 não houve diferenças. Porém, verificou-se aumento dos teores desse nutriente nos SAF10 (45\%), ACQ (48\%) e FN (41\%) em relação ao obtido no período chuvoso. Entre os períodos de coleta, os teores de $\mathrm{K}$ nos sistemas apresentaram significativa diferença (Tabela 3). Em relação aos teores de Ca das folhas, não houve diferença entre os sistemas no período chuvoso. Porém, no período seco o Ca apresentou maior teor $(\mathrm{p} \leq 0,05)$ no SAF10; entre os períodos, os teores de Ca foram estatisticamente diferentes. Entretanto, a maior concentração de $\mathrm{Mg}\left(5,3 \mathrm{~g} \mathrm{~kg}^{-1}\right)$ nas folhas foi obtida pelo SAF6 no período chuvoso. No período seco, os maiores teores de $\mathrm{Mg}(\mathrm{p} \leq 0,05)$ foram verificados no SAF10 $\left(4,1 \mathrm{~g} \mathrm{~kg}^{-1}\right)$, diferindo significativamente dos demais sistemas. Em relação ao período de coleta, apenas no SAF10 não houve diferença (Tabela 3).

Na fração galhos, foram observadas diferenças significativas nos teores dos nutrientes em relação aos sistemas e períodos de coletas. $\mathrm{O} \mathrm{N}$ foi o nutriente

Tabela 3 - Teores de N, P, K, Ca e Mg na fração folhas da serapilheira acumulada nos períodos chuvoso e seco, sob sistema ecológico com três anos (SE3), sistemas agroflorestais com seis (SAF6) e 10 anos (SAF10), agricultura de corte e queima (ACQ) e floresta nativa (FN).

Table 3 - Contents of $N, P, K, C a$ and $M g$ in the leaf fraction of litter accumulated during wet and dry seasons, under three-year old ecological system (ES3), agroforest systems with six (AFS6) and ten years (AFS10), slash-andburn agriculture (SBA) and native forest $(N F)$.

\begin{tabular}{|c|c|c|c|c|c|}
\hline \multicolumn{6}{|c|}{ Período Chuvoso } \\
\hline Sistemas & $\mathrm{N}$ & $\mathrm{P}$ & $\mathrm{K}$ & $\mathrm{Ca}$ & $\mathrm{Mg}$ \\
\hline \multicolumn{6}{|c|}{$\mathrm{g} \mathrm{kg}-1^{1}$} \\
\hline SE3 & $17,0 \mathrm{bA}$ & 2,7 aA & 6,9 aA & 10,9 aA & $3,9 \mathrm{abA}$ \\
\hline SAF6 & $19,2 \mathrm{abA}$ & 2,7 aA & 5,9 aA & $11,5 \mathrm{aA}$ & 5,3 aA \\
\hline SAF10 & 22,2 aA & 3,0 aA & $2,8 \mathrm{bA}$ & $11,5 \mathrm{aA}$ & $3,3 \mathrm{bA}$ \\
\hline ACQ & $16,8 \mathrm{bA}$ & $1,7 \mathrm{bA}$ & $2,4 \mathrm{bA}$ & 9,4 aA & $3,2 \mathrm{bA}$ \\
\hline $\mathrm{FN}$ & $12,0 \mathrm{cA}$ & $1,4 \mathrm{bA}$ & $2,3 \mathrm{bA}$ & $10,5 \mathrm{aA}$ & $2,3 \mathrm{bA}$ \\
\hline \multicolumn{6}{|c|}{ Período Seco } \\
\hline SE3 & $13,7 \mathrm{bB}$ & $5,3 \mathrm{abB}$ & 7,3 aA & $10,8 \mathrm{bA}$ & $2,5 \mathrm{bcB}$ \\
\hline SAF6 & $13,7 \mathrm{bB}$ & $6,0 \mathrm{abB}$ & 6,1 abA & $12,0 \mathrm{bA}$ & $3,5 \mathrm{abB}$ \\
\hline SAF10 & $18,2 \mathrm{aB}$ & $6,2 \mathrm{aB}$ & $6,5 \mathrm{abB}$ & $18,0 \mathrm{aB}$ & 4,1 aA \\
\hline ACQ & $13,8 \mathrm{bA}$ & $5,2 \mathrm{abB}$ & $4,9 \mathrm{abB}$ & $13,8 \mathrm{bB}$ & $1,9 \mathrm{cB}$ \\
\hline FN & $12,9 \mathrm{bA}$ & $5,5 \mathrm{abB}$ & $5,6 \mathrm{abB}$ & $12,0 \mathrm{bA}$ & $3,3 \mathrm{abB}$ \\
\hline
\end{tabular}

Médias seguidas de letras minúsculas diferentes na coluna (entre sistemas) e letras maiúsculas diferentes na coluna (entre períodos) indicam diferenças significativas pelo teste de Tukey a $5 \%$ de probabilidade. 
Tabela 4 - Teores de N, P, K, Ca e Mg na fração galhos da serapilheira acumulada nos períodos chuvoso e seco, sob sistema ecológico com três anos (SE3), sistemas agroflorestais com seis (SAF6) e dez anos (SAF10), agricultura de corte e queima (ACQ) e floresta nativa (FN).

Table 4-Contents of $\mathrm{N}, \mathrm{P}, \mathrm{K}, \mathrm{Ca}$ and $\mathrm{Mg}$ in the branch fraction of litter accumulated during wet and dry seasons, under three-year old ecological system (ES3), agroforest systems with six (AFS6) and ten years (AFS1O), slash-andburn agriculture (SBA) and native forest (NF).

\begin{tabular}{|c|c|c|c|c|c|}
\hline \multicolumn{6}{|c|}{ Período Chuvoso } \\
\hline Sistemas & $\mathrm{N}$ & $\mathrm{P}$ & $\mathrm{K}$ & $\mathrm{Ca}$ & $\mathrm{Mg}$ \\
\hline \multicolumn{6}{|c|}{$\longrightarrow \mathrm{g} \mathrm{kg}^{-1} \longrightarrow$} \\
\hline$\overline{\text { SE3 }}$ & $13,0 \mathrm{bA}$ & 1,9 aA & 4,0 aA & $6,9 \mathrm{bA}$ & 3,1 aA \\
\hline SAF6 & $12,8 \mathrm{bA}$ & 2,1 aA & 4,1 aA & $7,3 \mathrm{bA}$ & 3,5 aA \\
\hline SAF10 & 16,9 aA & 2,2 aA & 4,0 aA & $11,5 \mathrm{aA}$ & 3,1 aA \\
\hline ACQ & $10,6 \mathrm{bA}$ & $1,5 \mathrm{abA}$ & $0,8 \mathrm{bA}$ & $6,2 \mathrm{bA}$ & $1,6 \mathrm{bA}$ \\
\hline FN & $10,9 \mathrm{bA}$ & $0,8 \mathrm{bA}$ & $0,4 \mathrm{bA}$ & 13,8 aA & $1,8 \mathrm{bA}$ \\
\hline \multicolumn{6}{|c|}{ Período Seco } \\
\hline$\overline{\text { SE3 }}$ & $9,7 \mathrm{aB}$ & $6,2 \mathrm{aB}$ & $9,2 \mathrm{aB}$ & $13,1 \mathrm{aB}$ & $2,9 \mathrm{abA}$ \\
\hline SAF6 & $11,4 \mathrm{aA}$ & $6,2 \mathrm{aB}$ & $9,3 \mathrm{aB}$ & $12,0 \mathrm{aB}$ & $2,9 \mathrm{abA}$ \\
\hline SAF10 & $12,8 \mathrm{aB}$ & $6,2 \mathrm{aB}$ & $7,7 \mathrm{abB}$ & 12,9 aA & $3,1 \mathrm{aA}$ \\
\hline ACQ & $10,4 \mathrm{aA}$ & $6,0 \mathrm{aB}$ & $6,2 \mathrm{bcB}$ & $12,2 \mathrm{aB}$ & $1,8 \mathrm{cA}$ \\
\hline FN & $10,4 \mathrm{aA}$ & $5,3 \mathrm{aB}$ & $4,1 \mathrm{cB}$ & $9,9 \mathrm{aB}$ & $2,1 \mathrm{bcA}$ \\
\hline
\end{tabular}

Médias seguidas de letras minúsculas diferentes na coluna (entre sistemas) e letras maiúsculas diferentes na coluna (entre períodos) indicam diferenças significativas pelo teste de Tukey a $5 \%$ de probabilidade.

observado em maiores concentrações, comparativamente aos demais. Em relação aos sistemas, no SAF10 foram verificados os maiores teores ( $\mathrm{p} \leq 0,05)$ de N, P, Ca, $\mathrm{K}$ e Mg. No período seco, o N se destacou por apresentar maiores concentrações na fração galhos, embora tenha mostrado diminuição em relação ao período chuvoso. Em relação aos períodos de coletas, apenas os sistemas SE3 e SAF10 apresentaram diferenças. Quanto ao P no período chuvoso, apenas a FN $\left(0,8 \mathrm{~g} \mathrm{~kg}^{-1}\right)$ diferiu dos demais por obter o menor teor desse nutriente, assim como diferença significativa entre os períodos de coletas (Tabela 4).

No período chuvoso, os teores de $\mathrm{K}$ da fração galhos observados no ACQ $\left(0,8 \mathrm{~g} \mathrm{~kg}^{-1}\right)$ e FN $\left(0,4 \mathrm{~g} \mathrm{~kg}^{-1}\right)$ foram significativamente inferiores aos obtidos pelos demais sistemas, enquanto no período seco apenas os SE3 e SAF6 não se diferenciaram. Em relação aos períodos de coletas, houve diferença dos teores de K nos sistemas. Em Ca no período chuvoso, as maiores concentrações foram obtidas por SAF10 (11,5 $\left.\mathrm{g} \mathrm{kg}^{-1}\right)$ e FN $\left(13,8 \mathrm{~g} \mathrm{~kg}^{-1}\right)$, diferindo significativamente dos demais sistemas. Em geral, no que se refere ao teor de Ca na fração galhos, como foi verificado nas folhas, esse nutriente apresentou o segundo maior valor, em ambos os períodos de coleta. Considerando os teores de $\mathrm{Ke} \mathrm{Ca}$, verificou-se aumento dos teores no período seco, exceto de Ca na FN, que obteve menor teor. Entre os períodos de coletas, observou-se que apenas o SAF10 não apresentou diferença significativa dos teores de $\mathrm{Ca}$. Os teores de Mg obtidos no período chuvoso mostraram similaridade entre os sistemas SAF10, SAF6 e SE3, com valores superiores ao ACQ e FN. O Mg foi o nutriente que apresentou os menores teores no período seco e entre os nutrientes, menor variação, não diferindo estatisticamente em relação ao período de coleta (Tabela 4). Em ambos os períodos de coletas, foram observadas variações nas concentrações de nutrientes das frações da serapilheira, assim como houve variação nos estoques dessas frações.

Os valores estimados dos nutrientes devolvidos pela serapilheira acumulada nas frações folhas e galhos indicam a superioridade do SAF10 por meio da contribuição de nutrientes na serapilheira, em relação aos demais sistemas agrícolas. A maior quantidade de nutrientes foi obtida pela fração folhas. $\mathrm{O} N$ foi o nutriente que mais contribuiu entre os sistemas, seguido pelo $\mathrm{Ca}$. Os maiores valores desses elementos foram observados nos SAF10 e FN. No que se refere a P e $\mathrm{K}$ na fração folhas, o maior aporte desses nutrientes foi observado na FN. O SAF10 e FN foram os sistemas que apresentaram maiores aportes de $\mathrm{Mg}$. Na fração galhos, o SAF10 superou todos os sistemas quanto 
Tabela 5 - Estimativa anual do aporte nutricional da serapilheira nas frações amostradas ao solo $\left(\mathrm{kg} \mathrm{ha}^{-1}\right)$, sob sistema ecológico com três anos (SE3), sistemas agroflorestais com seis (SAF6) e dez anos (SAF10), agricultura de corte e queima (ACQ) e floresta nativa (FN).

Table 5 - Annual estimate of litter nutritional contribution in the sampled fractions $\left(\mathrm{kg} \mathrm{h}^{-1}\right)$, under three-year old ecological system (ES3), agroforest systems with six (AFS6) and ten years (AFS10), slash-and-burn agriculture (SBA) and native forest $(N F)$.

\begin{tabular}{|c|c|c|c|c|c|}
\hline \multicolumn{6}{|c|}{ Folhas } \\
\hline Sistemas & $\mathrm{N}$ & $\mathrm{P}$ & $\mathrm{K}$ & $\mathrm{Ca}$ & $\mathrm{Mg}$ \\
\hline \multicolumn{6}{|c|}{$-\mathrm{kg} \mathrm{ha}^{-1}$} \\
\hline SE3 & 40,1 & 11,0 & 18,9 & 28,6 & 8,3 \\
\hline SAF6 & 58,9 & 18,1 & 22,6 & 44,4 & 15,6 \\
\hline SAF10 & 111,1 & 25,3 & 25,5 & 81,1 & 20,3 \\
\hline ACQ & 62,3 & 19,3 & 18,8 & 55,5 & 9,4 \\
\hline $\mathrm{FN}$ & 72,7 & 22,1 & 24,6 & 65,1 & 16,8 \\
\hline \multicolumn{6}{|c|}{ Galhos } \\
\hline$\overline{\text { SE3 }}$ & 19,7 & 5,6 & 12,8 & 15,0 , & $\overline{5,0}$ \\
\hline SAF6 & 13,5 & 4,4 & 8,3 & 10,5 & 3,6 \\
\hline SAF10 & 48,3 & 11,1 & 14,0 & 37,3 & 9,7 \\
\hline ACQ & 7,7 & 3,3 & 3,6 & 7,5 & 1,3 \\
\hline FN & 20,0 & 5,2 & 5,8 & 22,7 & 3,6 \\
\hline
\end{tabular}

ao aporte dos nutrientes. Como observado nas folhas, o nutriente que mais contribuiu foi o $\mathrm{N}$, enquanto a menor contribuição foi obtida pelo $\mathrm{Mg}$. O retorno desses nutrientes, através da serapilheira, encontra-se na seguinte ordem: $\mathrm{N}>\mathrm{Ca}>\mathrm{K}>\mathrm{P}>\mathrm{Mg}$ (Tabela 5),

\section{DISCUSSÃO}

A estimativa de maior estoque de serapilheira acumulada na fração folhas observado no SAF10 em relação aos demais sistemas pode ser atribuída à maior quantidade e diversidade vegetal desse sistema. Outros autores, ao avaliarem estoques de serapilheira em SAFs comparativamente à capoeira e mata, observaram comportamento semelhante quanto à superioridade do SAF em relação ao estoque de serapilheira (SILVA, 2006; PENEIREIRO, 1999). No ACQ, o aumento da serapilheira ocorreu em virtude da regeneração da vegetação secundária. O maior acúmulo da fração folhas na FN e ACQ no final do período seco provavelmente está associado às características fisiológicas das espécies vegetais dessas áreas e ao déficit hídrico, uma vez que a queda das folhas reduziria a perda de água por transpiração. Além disso, deve-se considerar o manejo com o roço, assim como a poda das espécies arbóreas, que começa a ser realizado por parcelas antes do período das chuvas, contribuindo para o aumento de material vegetal na serapilheira. Arato et al. (2003) observaram maior quantidade de serapilheira no final da estação seca, em um sistema agroflorestal em Viçosa, MG, o que atribuíram à ausência de chuvas nesse período, que resultou na resposta da vegetação ao estresse hídrico, em termos de máxima deposição de serapilheira.

O maior aporte de biomassa no período chuvoso, observado no sistema SAF10, equivalente à quantidade produzida numa área nativa sem interferência antrópica, evidencia que a qualidade nutricional do solo poderá ser influenciada pela quantidade de serapilheira acumulada e a concentração de seus nutrientes. De acordo com Schumacher et al. (2004), a quantidade de serapilheira e seu teor de nutrientes aportados ao solo, pelo povoamento, irão refletir na sua capacidade produtiva e no seu potencial de recuperação ambiental, considerando-se as modificações que irão ocorrer nas características químicas do solo.

Levando-se em conta a importância do aporte de nitrogênio para a agricultura, os maiores teores de nitrogênio (N) na fração folhas observados no SAF10, em ambos os períodos de coletas, provavelmente estejam relacionados ao maior estoque da serapilheira, decorrente da diversidade vegetal desse sistema, em que o consórcio de espécies agrícolas, entre essas leguminosas e espécies florestais, favoreceria o aumento do teor de $\mathrm{N}$ por meio da fixação biológica, em relação aos demais sistemas. Além disso, podem estar associados à presença de frações jovens (principalmente folhas) provenientes da poda e roço ou que sofreram abscisão nesse período de chuvas e contribuíram para a formação da serapilheira depositada (SOUTO, 2006).

R. Árvore, Viçosa-MG, v.34, n.1, p.75-84, 2010 
O fósforo $(\mathrm{P})$, por ser nutriente de elevada redistribuição interna, é encontrado em grande parte nas folhas em plena atividade metabólica. Nesse sentido, o maior teor de P no SAF10 pode ser atribuído à adição de biomassa em diferentes estágios de maturação decorrente do manejo, visto que durante a poda os nutrientes não foram translocados internamente pela planta, como ocorre no processo de abscisão foliar (SILVEIRA et al., 2007). Em relação às menores concentrações de $\mathrm{P}$ na fração folhas, comparativamente ao observado nos demais nutrientes no período chuvoso, é similar ao verificado por Santana (2005) em área de Caatinga.

Os maiores teores de $\mathrm{K}$ da fração folhas no período seco pode estar relacionado ao aporte desse nutriente, devido ao consorcio de algumas espécies cultivadas. Silveira et al. (2007) atribuíram a maior concentração de $\mathrm{K}$ ao cultivo de bananeiras, considerando a maior concentração desse nutriente nas folhas e frutos da espécie, porém, neste estudo, essa relação não pôde ser considerada, pois os SE3 e SAF6 apresentaram menor quantidade dessa espécie, em relação ao SAF10. Resultados semelhantes foram observados por Kolm e Poggiani (2003), que estudaram o retorno de nutrientes ao solo pela produção de serapilheira em plantações de Eucalyptus grandis, na região Centro-Sul de São Paulo. Observaram maior teor de K no período seco. Esse resultado foi atribuído a uma redução no processo de translocação desse elemento das folhas caducas para as mais novas.

A concentração de Ca na fração folha foi menor apenas que a concentração de $\mathrm{N}$ e pode estar relacionada à menor mobilidade do Ca na planta (constituinte da parede celular), portanto não é translocado para tecidos mais jovens (KÖNIG et al., 2002). O SAF10 difere dos demais sistemas agrícolas, pela quantidade e diversidade do componente arbóreo que favorece a maior quantidade e diversidade de folhas senescentes, além do material depositado após o manejo, e isso pode explicar a maior concentração de Ca na serapilheira desse sistema em relação aos demais no período seco.

Neste estudo, as menores concentrações de $\mathrm{Mg}$ observadas na floresta nativa em relação aos SAFs indicam que o manejo agroflorestal favoreceu um bom incremento desse nutriente. Outros autores verificaram maiores teores de $\mathrm{Mg}$ em áreas de florestas, em relação ao SAF, como Santana (2005) em área remanescente

R. Árvore, Viçosa-MG, v.34, n.1, p.75-84, 2010 de Caatinga arbóreo-arbustiva no Rio Grande do Norte e Souto (2006) em área de Caatinga no semiárido paraibano. Esses autores observaram teores elevados de Mg na fração folhas.

Em geral, os valores de $\mathrm{P}$ obtidos no período chuvoso foram inferiores aos outros nutrientes. Santana (2005) constatou baixos valores de P na fração galhos e associou isso ao fato de o fósforo ser elemento constituinte de compostos complexos, ricos em energia e facilmente retranslocado dos tecidos mais velhos para os mais novos da planta. Com isso, as maiores concentrações poderiam ser observadas nas folhas novas. Os teores de P nos sistemas foram praticamente o triplo dos verificados no período chuvoso, o que pode ser associado à permanência desse nutriente nos galhos, uma vez que grande parte da vegetação perde as folhas nesse período, em virtude do estresse hídrico. Os menores teores de $\mathrm{K}$ no período chuvoso são geralmente esperados, em virtude de esse elemento ser componente do suco celular e facilmente lixiviável com a chuva (SCHUMACHER et al., 2004). Nesse sentido, os teores de $\mathrm{K}$ no período seco podem confirmar a maior concentração desse nutriente pela ausência das chuvas, o que resulta na lixiviação do K para o solo.

A concentração de $\mathrm{Ca}$ na fração galhos foi semelhante à observada na fração folhas e pode ser relacionada à baixa mobilidade no tecido vegetal, assim como sua associação à lignificação e constituição de paredes celulares (SCHUMACHER et al., 2004). Os menores teores de $\mathrm{Mg}$ na fração galhos podem ser explicados pela participação desse elemento na constituição da clorofila a e b, por esse motivo a maior concentração é observada nas folhas, em detrimento dos outros componentes da planta. Os teores de nutrientes verificados neste estudo podem indicar a influencia da serapilheira na dinâmica nutricional dos sistemas, em virtude das mudanças decorrentes de diferentes fatores, como manejo, clima e as características fisiológicas das espécies.

No que se refere ao retorno dos nutrientes pela serapilheira acumulada, a maior contribuição observada no SAF10 pela fração folhas, pode ser atribuída ao fato de que essa fração é a principal componente da serapilheira, tanto em quantidade (conteúdo de nutrientes devolvidos) quanto em concentração (KÖNIG et al., 2002). Esses autores observaram resultados similares ao analisar a devolução de nutrientes via serapilheira em um fragmento de Floresta 
Estacional Decidual no Município de Santa Maria, RS. Os valores estimados da concentração de nutrientes ao solo via serapilheira acumulada evidenciaram a menor contribuição de $\mathrm{Mg}$ em ambos os períodos de coleta, porém não significa que esse elemento seja limitante na produtividade do ecossistema. Além disso, no solo existem níveis significativos de magnésio que podem suprir as necessidades das plantas (SANTANA, 2005). Esse resultado difere do observado por König et al. (2002), que verificaram maior aporte de nutrientes na fração galhos pelo Ca e o menor valor de devolução obtido pelo $\mathrm{P}$.

A ordem da estimativa anual do aporte de nutrientes, obtidos nas frações folhas e galhos em ambos os períodos, indica que o manejo e a composição vegetal no sistema agroflorestal com 10 anos de adoção proporcionaram incremento significativo no aporte de nutrientes ao solo, via serapilheira, em relação aos outros agroecossistemas estudados. Os valores no SAF10 superaram os verificados na FN, sugerindo a validação do sistema no qual o manejo favorece o aumento de nutrientes provenientes da serapilheira ao solo.

\section{CONCLUSÕES}

O SAF10 proporcionou maior aporte de biomassa no solo em relação aos outros agroecossistemas estudados e equivalentes à quantidade produzida na FN.

As concentrações de N, P, K, Ca e Mg nas frações da serapilheira apresentaram diferenças sazonais nos sistemas, entretanto com $\mathrm{N}$ e Ca em maiores concentrações especialmente no SAF10.

O maior valor de estoque nutricional no SAF10 reflete a importância da serapilheira para a manutenção da sustentabilidade desse sistema, que pode ser considerado como mais promissor em relação aos demais sistemas estudados.

\section{REFERÊNCIAS}

ALVES, B. J. R. et al. Emprego de isótopos estáveis para o estudo do carbono e do nitrogênio no sistema solo-planta. In: AQUINO, A. M.; ASSIS, R. L. (Eds.) Processos biológicos no sistema solo-planta. Brasília, DF: Embrapa Informação Tecnológica, 2005. p.343-368.
ARATO, H. D.; MARTINS, S. V.; FERRARI, S. H. S. Produção e decomposição de serapilheira em um sistema agroflorestal implantado para recuperação de área degradada em Viçosa-MG. Revista Árvore, v.27, n.5, p.715-721, 2003.

BORÉM, R. A. T.; RAMOS, D. P. Variação estacional e topográfica de nutrientes na serapilheira de um fragmento de mata atlântica. Cerne, v.8, n.2, p.42-59, 2002.

COSTA, G. S. et al. Aporte de nutrientes pela serapilheira em uma área degradada e revegetada com leguminosas arbóreas. Revista Brasileira de Ciência do Solo, v. 28, n.5, p.919-927, 2004.

EMPRESA BRASILEIRA DE PESQUISA AGROPECUÁRIA - EMBRAPA. Centro Nacional de Pesquisa de Solos Manual de métodos de análise de solos. 2.ed. Rio de Janeiro: 1997. 212p.

FIGUEIREDO FILHO, A. et al. Avaliação estacional da deposição de serapilheira em uma floresta ombrófila mista localizada no sul do estado do Paraná. Ciência Florestal, v.13, n.1, p.11-18, 2003.

HOBBELEN, P. H. F.; van GESTEL, C. A. M. Using dynamic energy budget modeling to predict the influence of temperature and food density on the effect of $\mathrm{Cu}$ on earthworm mediated litter consumption. Ecological Modelling, v.202, n.3/4, p.373-384, 2007.

KOLM, L.; POGGIANI, F. Ciclagem de nutrientes em povoamentos de Eucalyptus grandis submetidos à prática de desbastes progressivos. Scientia Forestalis, n.63, p.79-93, 2003.

KÖNIG, F. G. et al. Devolução de nutrients via serapilheira em um fragmento de floresta estacional decidual no município de Santa Maria, RS. Brasil Florestal, v.72, p.45-52, 2002.

LIMA, S. S. Impacto do manejo agroflorestal sobre a dinâmica e nutrientes e a macrofauna invertebrada nos compartimentos serapilheira-solo em área de transição no norte do Piauí. 2008. 76f. Dissertação (Mestrado em

Desenvolvimento e Meio Ambiente) -

Universidade Federal do Piauí, Teresina, 2008.

R. Árvore, Viçosa-MG, v.34, n.1, p.75-84, 2010 
LOUZADA, J. N. C.; MACHADO, F. S.; van den BERG, E. O fogo como instrumento de manejo em agroecossistemas. Informe Agropecuário, v.24, n.220, p.29-36, 2003.

MENDONZA, H. N. S. et al. Propriedades químicas e biológicas de solo de tabuleiro cultivado com cana-de-açúcar com e sem queima da palhada. Revista Brasileira de Ciência do Solo, v.24, NUMERO, p.201-207, 2000.

PENEIREIRO, F. M. Sistema Agroflorestal dirigidos pela sucessão natural: um estudo de caso. 1999. 149f. Dissertação (Mestrado em Desenvolvimento e Meio Ambiente) - Escola Superior de Agricultura Luiz de Queiroz, Piracicaba, 1999.

POLYAKOVA, O.; BILLOR, N. Impact of deciduous tree species on litterfall quality, decomposition rates and nutrient circulation in pine stands. Forest Ecology and Management, v.253, n.1/3, p.11-18, 2007.

SANTANA, J. A. S. Estrutura

fitossociológica, produção de serapilheira e ciclagem de nutrientes em uma área de Caatinga no Seridó do Rio Grande do Norte. 2005. 184f. Tese - Universidade Federal da Paraíba, Areia, 2005.

SANTOS, H. G. et al. (Ed). Sistema brasileiro de classificação de solos. 2.ed. Centro Brasileiro de Pesquisa do Solo. Rio de Janeiro: Embrapa Solos, 2006. 306p.
SCHUMACHER, M. V. et al. Retorno de nutrientes via deposição de serapilheira em um povoamento de acácia-negra (Acacia mearnsii De Wild.) no estado do Rio Grande do Sul. Revista Árvore, v.27, n.6, p.791-798, 2003.

SCHUMACHER, M. V. et al. Produção de serapilheira em uma floresta de Araucaria angustifolia (bertol.) Kuntze no município de Pinhal Grande-RS. Revista Árvore, v.28, n.1, p.29-37, 2004.

SILVA, M. S. C. Indicadores de qualidade do solo em sistemas agroflorestais em Paraty, RJ. 2006. 54f. Dissertação - Universidade Federal Rural do Rio de Janeiro, Seropédica, 2006.

SILVEIRA, N. D. et al. Aporte de nutrientes e biomassa via serapilheira em sistemas agroflorestais em Paraty (RJ). Ciência Florestal, v.17, n.2, p.129-136, 2007.

SOUTO, P. C. Acumulação e decomposição da serapilheira e distribuição de organismos edáficos em área de caatinga na Paraíba, Brasil. 150f. 2006. Tese - Universidade Federal da Paraíba, Areia, 2006.

VOHLANDA, K.; SCHROTHB, G. Distribution patterns of the litter macrofauna in agroforestry and monoculture plantations in central Amazonia as affected by plant species and management. Applied Soil Ecology, v.13, n.1, p.57-68, 1999. 